\title{
SUSANA ÁLVAREZ DE NEYRA KAPPLER: LA PROTECCIÓN DEL DERECHO A LA INTIMIDAD EN LA TOMA DE MUESTRAS DE ADN A FINES DE INVESTIGACION PENAL ${ }^{1}$
}

\section{PROTECTING THE RIGHT TO PRIVACY IN DNA SAMPLING FOR THE PURPOSES OF CRIMINAL INVESTIGATION}

\begin{abstract}
RESUMEN: En el ámbito del derecho a la intimidad es donde se manifiesta más claramente la tensión entre los derechos individuales y el interés general en el ámbito de la investigación penal a través de marcadores de ADN, pues todo contacto físico supone inevitablemente traspasar los límites de la personalidad humana. La intimidad lato sensu no es un bien jurídico de fácil definición porque engloba, no sólo el concepto de la esfera íntima en la que se incluyen las facultades clásicas de exclusión de terceros, sino que afecta a todos los derechos de la personalidad. Debemos distinguir a su vez entre la intimidad corporal y la intimidad personal, incluyendo, dentro de esta última, la llamada intimidad genética, que es la más vulnerable en este tipo de diligencias de investigación penal y que por ello necesita de una protección reforzada.
\end{abstract}

\begin{abstract}
In the area of the right to privacy is where the tension between individual rights and the general interest in the field of criminal investigation through DNA markers is most clearly manifested, as physical contact means inevitably overstep the limits of human personality. Lato sensu privacy is not an easy legal definition because it encompasses not only the concept of the private sphere in which the classical powers of exclusion of third parties are included, but affects all personality rights. We must distinguish also between the physical intimacy and personal privacy, including, within the latter, the so-called genetic privacy, which is the most vulnerable in this type of criminal investigations and therefore needs an increased protection.
\end{abstract}

PALABRAS CLAVE: Derecho fundamental a la intimidad, intimidad corporal, intimidad personal, intimidad genética, prueba de ADN, investigación penal.

KEYWORDS: Fundamental right to privacy, physical privacy, personal privacy, genetic privacy, DNA testing, criminal investigation.

\section{INTRODUCCIÓN: EL DERECHO A LA INTIMIDAD Y LOS AVANCES EN MATERIA DE IDENTIFICACIÓN GENÉTICA}

Una conquista indudable de la biología molecular ha sido la posibilidad de determinar positivamente la herencia genética de las personas, que se ha

\footnotetext{
${ }^{1}$ Prof ${ }^{a}$ Contr. Dra. Universidad Autónoma de Madrid.
} 
DOI: http://dx.doi.org/10.12795/IETSCIENTIA.2017.i01.06

utilizado no sólo a fines de investigación científica o humanitarios, sino también en el proceso penal para ayudar al descubrimiento del autor de los hechos.

En nuestro país, la policía científica española empezó a trabajar con muestras de ADN a principios de los años noventa, por lo que se cumplen ya más de dos décadas desde el primer informe emitido por la Sección de Biología del Instituto de Toxicología de Madrid, en el que por vez primera se utilizó la tecnología del ADN en España ${ }^{2}$. A día de hoy podemos afirmar que los laboratorios acreditados en España están en perfectas condiciones de aplicar la compleja tecnología del ADN como método de identificación genética con plenas garantías de fiabilidad ${ }^{3}$.

La irrupción del ADN entre los criminalistas provocó toda una revolución ${ }^{4}$, hasta el punto de que algunos autores han definido el ADN como

\footnotetext{
${ }^{2}$ En la investigación de un presunto delito de violación Fue en 1.991, y los resultados fueron exculpatorios. De lo que no cabe duda, es de que la trascendencia de la prueba en el proceso penal en la investigación de delitos graves y de su autoría han hecho necesario el desarrollo de un marco legal mínimo que regulara esta materia, de los aspectos básicos o de mayor importancia de esta materia, garantizando la protección de determinados derechos de la persona.

${ }^{3}$ Es de interés destacar la Sentencia del Tribunal Supremo (STS) 1701/1992, de 13 de julio, absolutamente pionera en el tema, de la que fue Ponente RUIZ VADILLO, cuestionando la infalibilidad de este tipo de pruebas. De hecho, por aquél entonces, sólo se utilizaban 8 marcadores de ADN, y hoy día se analizan 18 marcadores más el sexo.

Según la citada sentencia, "el derecho a las pruebas no es, en ningún caso, un derecho a llevar a cabo una actividad probatoria ilimitada y las pruebas que las partes tienen derecho a practicar son las que guardan relación con el objeto del litigio (STC 89/1986, de 1 de julio), siempre que sean necesarias y pertinentes. (...) El análisis del ADN, medio probatorio que propuso (...) la defensa del acusado, y que fue declarada no procedente, lo fue porque está acreditado que dicha técnica estaba en período de experimentación (...) por lo que hasta ahora sus resultados no son fiables. Los Médicos Forenses (...), informaron que los marcadores genéticos hallados en las muestras examinadas son exactos y científicamente los análisis de la citada sustancia ADN no hubieran desvirtuado la presencia de aquellos marcadores en las expresadas muestras. (...) El procedimiento sobre investigación biológica mediante el análisis del ADN basado en el poliformismo genético individual, tiene un alto o altísimo poder de diagnóstico individual. (...) La ciencia distingue perfectamente bien entre posibilidad, probabilidad y certeza absoluta, expresión que casi nunca puede utilizarse y que en el campo del derecho es sustituida por la de certeza jurídica, que es la certidumbre a la que el derecho, a través de sus jueces, puede llegar. (...) Aún hoy parece que, a pesar de la eficacia, algunos científicos expresan sus inquietudes respecto a la prueba llamada "huella genética" en los procesos judiciales. La genética es, sin duda, una Ciencia esencial en nuestros días pero que, en la actualidad, plantea importantes problemas e interrogantes".

${ }^{4}$ En general, los autores se muestran muy esperanzados con la prueba de ADN, resaltando la importancia de este medio probatorio. Así, en palabras de MORENO VERDEJO, que afirma que la huella genética ha supuesto "una revolución", dado que su grado de fiabilidad es "incomparable al proporcionado por otras pruebas". Vid., MORENO VERDEJO, J., en ADN y proceso penal: análisis de la reforma operada por la ley orgánica 15/2003, de 25 de noviembre, Ed. Centro de Estudios Jurídicos del Ministerio de Justicia. Publicaciones año 2006; en página web www.cej.justicia.es, pág. 1801 y ss.. En todo caso, no se debe caer en una "euforia criminalística" y pensar que con ello se va a conseguir rebajar el índice de criminalidad. Vid., STS 798/1999, que afirma que de la prueba del ADN "puede decirse que res ipsa loquitur; la cosa habla por sí misma". Otros, por contra, hablan del aumento de la "capacidad represiva del Estado".
} 
DOI: http://dx.doi.org/10.12795/IETSCIENTIA.2017.i01.06

la "prueba-estrella" de la investigación criminal ${ }^{5}$, desplazando del trono probatorio a la clásica prueba por testigos.

No obstante, y a diferencia de lo que ocurría en los países de nuestro entorno jurídico, España carecía de una mínima previsión legal sobre esta materia, laguna ${ }^{6}$ que quiso empezar a paliar la reforma de la Ley de Enjuiciamiento Criminal del año $2003^{7}$. Se daba nueva redacción a los arts. 326 y 363 de la ley, reglando el uso de las pruebas de ADN en la investigación penal, permitiendo que el juez instructor pudiera autorizar la toma de muestras de sospechosos de delitos graves ${ }^{8}$. Dicha reforma resultó claramente insuficiente y evidenciaba la necesidad de una norma multidisciplinar, extensa, que protegiera los derechos fundamentales que pudieren verse afectados, tanto de naturaleza material como estrictamente procesal. A ello tiende la aprobación de la Ley Orgánica $10 / 2007^{9}$, regulando la creación y la utilización de los macro-bancos de material identificativo, buscando la protección de los derechos fundamentales que pudieren verse afectados en su práctica.

Dentro de ese elenco de derechos que pueden verse limitados en la práctica de la toma de muestras genéticas a fines de investigación penal, destaca, entre otros, el derecho a la intimidad.

\footnotetext{
${ }^{5}$ No sólo a estos efectos. Piénsese también en la búsqueda de personas desaparecidas, en las grandes catástrofes para identificación de los fallecidos, etc.

Calificada como de una situación de anomia por algunos autores. Vid., MORENO VERDEJO, J., y GUILLEN VAZQUEZ, M., en ADN y proceso jurisdiccional: excesos y defectos: necesidad de superar la actual situación de anomalía, en Revista de Derecho Penal - Práctica Penal, Ed. SEPIN (Penal), no 1, enero-febrero 2.003, págs. 45 y ss.

${ }^{7}$ Es por ello que la parálisis legislativa era difícilmente explicable. En palabras de ASENCIO MELLADO, "Ia falta de regulación coloca a nuestro proceso penal en una franca situación de desubicación temporal y lo lleva a límites de ineficacia", en Derecho Procesal Penal, Ed. Tirant lo Blanch, Valencia, 1988, pág, 167. Esta laguna también es duramente criticada por el propio TS en STS de 4 de junio de 2003, afirmando que "de forma ciertamente incomprensible, por injustificada, el legislador español, a estas alturas, sigue manteniendo sustancialmente huérfana de regulación específica la práctica de actuaciones sobre el cuerpo humano". Calificada de "raquitismo normativo" en STS de 14 de febrero de 2006. Y ello no obstante las reiteradas advertencias del TEDH.

HERRERO-TEJEDOR incide en la misma idea, al afirmar que "pese a la importancia de este tema (...) brilla por su ausencia una mínima regulación de conjunto. Hay que acudir a una normativa fragmentaria y poco concreta. (...) La legislación no ha seguido el ritmo de los adelantos técnicos". Vid., HERRERO-TEJEDOR ALGAR, F., en Intervenciones corporales: jurisprudencia constitucional. Centro de Estudios Jurídicos del Ministerio de Justicia. Publicaciones año 2006; en página web www.cej.justicia.es, pág. 1891. Recordemos que este vacío lo viene a suplir la LO 10/2007.

${ }^{8}$ Véase Ley Orgánica $15 / 2003$, de 25 de noviembre, por la que se modifica la Ley Orgánica 10/1995, de 23 de noviembre, del Código Penal. Tal Ley Orgánica entró en vigor el día 1 de octubre de 2.004, con excepción, entre otras, de la Disposición Final Primera, afectante a la materia que nos ocupa. Puede consultarse al respecto, el trabajo de DEL MORAL GARCIA, A., en Intervenciones corporales: reflexiones ante la inminente enésima reforma de la Ley de Enjuiciamiento Criminal. Ponencia presentada al Curso Constitución y Garantías Penales, CGPJ, noviembre de 2003.

${ }_{9}$ De 8 de octubre, reguladora de la base de datos policial sobre identificadores obtenidos a partir del ADN.
} 


\section{INTIMIDAD ${ }^{10}$ \\ 2. DELIMITACIÓN DEL DERECHO FUNDAMENTAL A LA}

Es quizás en el ámbito de la protección a la intimidad donde se manifiesta más claramente la tensión entre los derechos del individuo sometido al proceso penal y el interés de la sociedad en investigar los hechos y la autoría, pues todo contacto físico supone inevitablemente traspasar los límites de la personalidad humana ${ }^{11}$.

Dar un concepto único de lo que debe entenderse por <<intimidad >> no es tarea sencilla pues engloba, según GIL HERNANDEZ ${ }^{12}$, no sólo el concepto de la esfera íntima en la que se incluyen las facultades clásicas de exclusión de terceros, sino que afecta a todos los derechos de la personalidad. Por ello el derecho a la intimidad debe proyectarse en una clásica doble vertiente: por una, "como libertad de vivir conforme a los gustos y preferencias de cada uno, pero, por otra, quedando limitada por la libertad de los demás"13. Sobre esta última vertiente deben fundamentarse las posibles limitaciones. Así lo ha entendido el $\mathrm{CEDH}^{14}$ y las decisiones de la Comisión Europea ${ }^{15}$, estableciéndose que, al no ser la intimidad un derecho absoluto, lo importante es la medida o proporción de la intromisión.

\section{a) La intimidad corporal y la intimidad personal}

La sentencia del Tribunal Constitucional (STC) 207/1996 distingue el derecho a la intimidad según el ámbito de la afectación, diferenciándose así entre el quebranto que la intimidad puede sufrir al realizarse una intervención corporal cuando la obtención de la muestra se produzca en las zonas íntimas del cuerpo (intimidad corporal), y el que se produce por la información que pudiere proporcionar el análisis genético de la muestra corporal ${ }^{16}$ (intimidad

10 Vid., art. 18.1 CE y $8.1^{\circ}$ del CEDH y STEDH $X$ e $Y$ vs. Holanda, de 26 de marzo de 1985 , y Costello Roberts vs. Reino Unido, de 25 de marzo de 1993, así como las Decisiones del CEDH núms. 8239/78 y 8278/78. Vid., asimismo, STS de 4 de junio de 2003 y STC 234/1997, de 18 de diciembre.

${ }^{11}$ NARVAEZ RODRIGUEZ, A., en ADN e investigación penal: su necesaria regulación legal, Revista del Centro de Estudios Jurídicos de la Administración de Justicia, 1 semestre de 2.003, oㅡ 2, pág. 47.

${ }_{12}$ GIL HERNANDEZ, A., en Intervenciones corporales y derechos fundamentales, Ed. Colex, 1995, págs. 44 y ss.

13 "Un límite de cada derecho es respetar el derecho de los demás". STC 2/1982.

${ }^{14} \mathrm{Vid}$., art. 8.2 $2^{\mathrm{a}}$, estableciendo lo requisitos para la limitación del derecho a la intimidad, como ya hemos tenido ocasión de recoger.

15 Decisiones de 4 de diciembre de 1978 y de 13 de diciembre de 1979.

16 Llama la atención la consecuencia que de la lectura de esta sentencia extrae MORENO VERDEJO, al decir que "por tanto, averiguar en un proceso penal a través de una prueba de ADN si una persona consume droga (caso de la STC 207/1996) o padece de una determinada enfermedad, afecta a la intimidad o al honor exactamente lo mismo que si se averigua este extremo a través de otro tipo de pruebas, como puede ser la testifical. La afectación de la intimidad no lleva a discutir que pueda recibirse declaración a un testigo por la policía como medio de averiguación del delito, sin necesidad de previa habilitación judicial, ni de resolución motivada, ni de ningún otro requisito esencial". Vid., MORENO VERDEJO, J., en $A D N$ y proceso penal: análisis de la reforma operada por la ley orgánica 15/2003, de 25 de noviembre, Ed. Centro de Estudios Jurídicos del Ministerio de Justicia. Publicaciones año 2006; en página web www.cej.justicia.es, pág. 1827 y ss. 
DOI: http://dx.doi.org/10.12795/IETSCIENTIA.2017.i01.06

personal). La intimidad personal tiene así un contenido más amplio que el de la intimidad corporal, implicando la existencia de un ámbito propio y reservado frente a la acción y el conocimiento de los demás.

En España debemos partir de que ambas esferas de la personalidad han sido garantizadas como derechos fundamentales independientes en nuestra Constitución de $1978^{17}$, por lo que la intimidad garantizada constitucionalmente como derecho fundamental no se limita a la intimidad corporal sino que abarca también la intimidad personal.

Respecto del ámbito de la intimidad corporal afirmaba el Tribunal Constitucional $^{18}$ que no es coextenso con el de la realidad física del cuerpo humano, afirmación que fue duramente criticada por la doctrina científica ${ }^{19}$. Según este sector crítico, la intimidad corporal queda reducida de este modo al recato 0 al pudor y sólo garantiza a la persona frente a intervenciones corporales que se produzcan en las zonas íntimas del cuerpo según un criterio cultural generalizado ${ }^{20}$. Así, desde la perspectiva de la intimidad corporal, no todas las partes del cuerpo merecen igual protección constitucional y no parece que se produzca la misma injerencia tratándose o no de zonas íntimas ${ }^{21}$.

En este sentido, el Tribunal Supremo entendía que las intervenciones e inspecciones corporales podían suponer una violación al derecho a la intimidad según qué caso: si la misma información puede obtenerse con medidas menos restrictivas de la intimidad ${ }^{22}$, habría que acudir a ellas, en aplicación del principio de proporcionalidad ${ }^{23}$.

17 Así lo ha reconocido a su vez la jurisprudencia en STC 297/1996, de 16 de diciembre, supuesto en el que el juez instructor ordenaba a un imputado someterse a una extracción de pelos de las axilas, para determinar si era consumidor habitual de cocaína o no. Para el TC, este requerimiento de soportar una intervención corporal puede incidir tanto en el derecho a la integridad física del art. 15 CE como a la intimidad personal del 18 de la CE.

${ }^{18}$ STC 37/1989.

${ }^{19}$ Vid., GONZALEZ-CUELLAR SERRANO, N., en Proporcionalidad y derechos fundamentales en el proceso penal, Ed. Colex, Madrid, págs. 286 y ss. LOPEZ BARJA DE QUIROGA, J., y RODRIGUEZ RAMOS, L., en La intimidad corporal devaluada.- Comentario a la sentencia $n^{\circ}$ $37 / 1989$ de 15 de febrero, del TC, en Poder Judicial, 1989, pág. 123; y GIL HERNANDEZ, A., en Intervenciones corporales y derechos fundamentales, Ed. Colex, Madrid, 1995, págs. 47-48.

${ }^{20}$ LOPEZ-FRAGOSO ALVAREZ entiende que las críticas a esta doctrina del TC no son merecidas. En primer lugar, porque no puede olvidarse el supuesto que resuelve esta sentencia: el reconocimiento médico de una mujer de la que se sospechaba había abortado voluntariamente. La sentencia no se ocupaba tanto de una intervención corporal, sino de una inspección corporal sobre zonas íntimas, asimilable a las exploraciones anales y vaginales. Vid, LÓPEZ-FRAGOSO ÁLVAREZ, T., en Principios y límites de las pruebas en el proceso penal, en la obra colectiva Genética y Derecho. Ed. CGPJ - Estudios de Derecho Judicial, Madrid, 2.001, págs. 148 y ss.

${ }_{21}$ En general, en los países de la common law, la atención se ha fijado tradicionalmente en la esfera de la privacy o derecho a la intimidad de los afectados, distinguiendo así entre muestras íntimas y muestras no íntimas, a diferencia de lo que ocurre en nuestro país y en otros sistemas de derecho continental, en los que las garantías ofrecidas a quien va a someterse a una diligencia de este tipo se regulan sobre la base de la diferencia entre la intervención y la inspección corporal.

${ }^{22}$ Resulta de interés destacar que esta sentencia incluye este tipo de datos en la intimidad de la persona, por lo que le afectaría el art. 8 del CEDH, admitiendo en estos casos la limitación del derecho a la intimidad, siempre que exista decisión judicial motivada y proporcional y se respete la dignidad de la persona.

${ }^{23}$ STS de 18 de enero de 1993, sobre la base de la propia STC 37/1989. 
DOI: http://dx.doi.org/10.12795/IETSCIENTIA.2017.i01.06

Teniendo en cuenta lo anterior, y con relación a las muestras de ADN, difícilmente podemos decir que se vea afectada la intimidad corporal por la toma de una muestra de ADN, dada la escasísima o nula injerencia corporal que supone para el investigado a día de hoy (un simple hisopo pasado por el interior de la cavidad bucal, una zona no íntima, si atendemos al criterio jurisprudencial aludido).

Respecto del derecho a la intimidad personal es necesario enmarcarlo como un derecho que garantiza a los particulares una esfera de libertad que debe ser respetada por los poderes públicos, para asegurarse de que las posibles limitaciones se produzcan con pleno respeto a las garantías debidas ${ }^{24}$, como un derecho de defensa frente al Estado para exigir su no injerencia ${ }^{25}$. $Y$ es el derecho a la intimidad en esta vertiente el que puede verse limitado a vulnerado en mayor medida cuando tratamos el tema de la obtención y el uso de vestigios genéticos en el proceso penal y que será objeto de nuestro estudio.

\section{b) La limitabilidad del derecho a la intimidad personal}

Al igual que ocurre con otros derechos fundamentales, tampoco el derecho a la intimidad personal es ilimitado ${ }^{26}$ y puede llegar a verse mitigado en ciertos casos ante necesidades públicas. Ello permite al juez instructor acordar la investigación del perfil genético del imputado a fines de investigación de un determinado hecho delictivo ${ }^{27}$.

Afirmaba la STC 73/1982 que no pueden considerarse violados los derechos a la intimidad personal "cuando se impongan limitaciones (...) como consecuencias de deberes y relaciones jurídicas que el ordenamiento jurídico regula" 28 .

La conocida STS ${ }^{29}$ de 15 de febrero de 1989, afirmaba igualmente la limitabilidad de este derecho, a pesar de que nuestra Carta Magna, al enunciarlo, no estableciera de modo expreso la reserva de intervención judicial. Según el Tribunal Supremo, la intimidad no puede erigirse en un obstáculo infranqueable frente a la indagación de la verdad material, pues "no cabe desconocer (...) las facultades legales que corresponden al instructor (...) para ordenar, en el curso de un sumario, la realización de exámenes periciales que, entre otros extremos, pueden versar sobre la descripción de la persona"30.

24 LOPEZ-FRAGOSO ALVAREZ, T., en Las intervenciones telefónicas en el proceso penal, Ed. Colex, Madrid, 1991, pág. 20 y ss.

${ }^{25}$ Salvo los supuestos de su limitación constitucionalmente previstos.

${ }^{26}$ Es importante tener clara la idea de que determinados derechos, por el hecho de ser considerados fundamentales, no se convierten por ello en sacrosantos e intocables, sino, que por el contrario, pueden ser limitados y su virtualidad restringida.

27 Los AATC de 9 de marzo y 31 de mayo de 1991 y la STC 7/1994, han desarrollado la doctrina constitucional sobre el carácter limitado de este derecho que en ningún caso puede ser utilizado como medio para consagrar la impunidad.

${ }^{28}$ Doctrina reiterada por las SSTC 170/1987, y 142/1993, entre otras.

${ }^{29}$ Sentencia del Tribunal Supremo. En adelante, STS.

30 En similar sentido, la STC de 17 de enero de 1994 dispone que no puede considerarse degradante, ni contraria a la dignidad de la persona, la verificación de un examen hematológico 
DOI: http://dx.doi.org/10.12795/IETSCIENTIA.2017.i01.06

En nuestro ordenamiento constitucional, toda limitación de un derecho con carácter de fundamental deberá respetar los siguientes condicionantes: sólo se podrá prever por ley orgánica (reserva de ley), sólo podrá emprenderse en defensa de bienes o derechos constitucionales; debe ser susceptible de alcanzar el fin perseguido (principio de idoneidad); debe comprobarse que no existe otra medida menos invasiva para alcanzar el fin propuesto (principio de necesidad); debe verificarse que la medida limitadora es ponderada 0 equilibrada por derivarse de ella más beneficios para el interés general que perjuicios para otros bienes en conflicto (principio de proporcionalidad en sentido estricto) ${ }^{31}$; las medidas limitadoras sólo se adoptarán por la autoridad judicial (principio de reserva jurisdiccional); y para ello se requerirá resolución debidamente motivada (auto), que plasme el juicio de ponderación entre el derecho fundamental afectado y el interés constitucionalmente perseguido y protegido, que demuestre la necesidad de la medida ${ }^{32}$.

En resumen, cuando se trate de una obligación impuesta judicialmente deberá tratarse de una medida prevista por la ley y que resulte proporcionada, pues sirve objetivamente para determinar hechos que constituyen el objeto de un proceso penal, siendo necesaria a este $\operatorname{~fin}^{34}$, sin que existan otras medidas menos gravosas e igualmente aptas para alcanzarlo, y siempre que el sacrificio que imponga no resulte excesivo en comparación con la gravedad que entraña.

Además, la decisión judicial deberá ser respetuosa de la dignidad de la persona y no puede constituir trato degradante alguno. Dicha decisión revestirá forma de auto motivado, con fundamento en una razonable apreciación de que la situación en que se halle el sujeto afectado requiera la práctica de dicha diligencia de investigación en relación con las exigencias de la actuación judicial en curso ${ }^{35}$.

por parte de un profesional de la medicina y que un examen de sangre no constituye una injerencia prohibida ni violación del pudor o recato.

${ }_{31}$ Es necesario destacar que en materia genética la información de que se llegue a disponer afectará no sólo al sujeto sometido a la medida, sino a todos sus descendientes y familiares por consanguinidad.

32 Tan es así que para HERRERO-TEJEDOR la falta de motivación "no provoca sin más una quiebra formal del derecho a la tutela judicial efectiva (...) sino que se produce una vulneración del contenido sustantivo del derecho fundamental". Vid., HERRERO-TEJEDOR ALGAR, F., en Intervenciones corporales: jurisprudencia constitucional. Centro de Estudios Jurídicos del Ministerio de Justicia, año 2006; en página web www.cej.justicia.es, pág. 1903.

${ }^{33}$ A pesar de esta falta de cobertura legal nuestros tribunales han admitido estas pruebas en casos tales como los siguientes:

- la identificación a través del cabello, en SSTS de 15 de marzo y 2 de diciembre de 1986, 24 de junio de 1991 y 24 de noviembre de 1993, considerando esta última que la negativa del inculpado requerido por el instructor, en presencia de letrado, a que se le cortasen unos cabellos, constituye un serio indicio para desvirtuar el principio de presunción de inocencia,

- la identificación por análisis de sangre, en STS de 11 de marzo de 1993,

- la identificación genética, en SSTS de 13 de julio de 1992, 24 de febrero de 1995, y de 21 de junio de 1994, anulando esta última la prueba por haber obtenido la muestra indubitada ordenándola en providencia y no en auto y con consentimiento viciado del afectado.

34 Para MORENO VERDEJO, la intimidad personal sólo se verá afectada cuando lo que se autorice sea el conocimiento de extremos innecesarios para la investigación penal. Vid., MORENO VERDEJO, J., en ADN y proceso penal..., op. cit., pág. 1826.

${ }_{35}$ En principio, el límite propio y típico de los derechos fundamentales, en cuanto manifestaciones de la libertad general de autodeterminación individual, es el consentimiento del 
DOI: http://dx.doi.org/10.12795/IETSCIENTIA.2017.i01.06

\section{c) La intimidad personal en sentido negativo y positivo}

Por la jurisprudencia se ha distinguido a su vez entre un sentido negativo de la intimidad, en cuanto exclusión del conocimiento de nuestros datos personales por los demás, y un sentido positivo, en cuanto control sobre dichos datos cuando éstos son compartidos. Es necesario proteger ambas vertientes de la intimidad personal.

\section{LA INTIMIDAD GENÉTICA ${ }^{36}$}

\section{a) Introducción}

Dentro del más amplio concepto de intimidad personal, podemos a su vez diferenciar entre la intimidad "personal" stricto sensu y la intimidad "genética", como una vertiente de la anterior, integrándose ambos derechos en la llamada "autodeterminación informativa", entendida ésta como la facultad que cada uno tiene de revelar o no determinados aspectos personales de su vida privada y en qué forma o momento desea o no hacerlo ${ }^{37}$. La información genética de cada individuo pertenece al reducto humano de la intimidad, reservada frente a injerencias extrañas ${ }^{38}$.

La utilización de las técnicas de análisis de ADN puede dar lugar a problemas técnicos y de interpretación, para lo cual la Sociedad Internacional de Genética Forense se erige como responsable de la promoción del conocimiento científico en el campo de los marcadores genéticos analizados con fines forenses.

Sin duda, estas tecnologías pueden reportar grandes beneficios, pero, a su vez, pueden ser origen de diversos abusos. La difusión de datos genéticos

titular $^{35}$. Además del consentimiento del titular, existen otras posibles limitaciones, recogidas en las normas internacionales:

- art. 8.2ำ Convenio Europeo Derechos Humanos (CEDH): "no podrá haber injerencia de la autoridad pública en el ejercicio de este derecho -(refiriéndose al respeto a la vida privada y familiar, domicilio y correspondencia)- sino en tanto en cuanto esta injerencia esté prevista por la ley y constituya una medida que, en una sociedad democrática, sea necesaria para la seguridad nacional, la seguridad pública, el bienestar económico del país, la defensa del orden y la prevención del delito, la protección de la salud o de la moral, o la protección de los derechos y las libertades de los demás.

- art. 9 Declaración Universal de los Derecho s Humanos (DUDH): sólo se admitirá si las limitaciones están "previstas por la ley, por razones imperiosas y dentro de los límites del derecho internacional público y del derecho internacional de los derechos humanos", y

- art. 26 del Convenio relativo a los derechos humanos y la biomedicina (CDHB): al considerar admisibles únicamente las limitaciones que, "previstas por la ley, constituyan medidas necesarias en una sociedad democrática, para la seguridad pública o la protección de los derechos y libertades de los demás".

${ }^{36}$ En ningún caso debe confundirse con la intimidad corporal, si por tal entendemos el recato personal. Vid. el estudio de LIBANO ALONSO sobre el Genoma Humano y la Medicina Forense. LIBANO ALONSO, A., en Bancos de archivos de perfiles de ADN. Revista de Derecho Médico y Legislación Sanitaria, año 1999.

${ }_{37} \mathrm{Si}$ intimidad corporal es igual a recato o pudor, aquella no sería equiparable, en consecuencia, a la intimidad genética.

${ }^{38}$ Vid., SSTC 103/1985, de 4 de octubre y $37 / 1989$, de 15 de febrero. 
DOI: http://dx.doi.org/10.12795/IETSCIENTIA.2017.i01.06

personales a terceras personas o a entidades (empresas, compañías de seguros, etc.) podría suponer un grave atentado a la intimidad y poner en peligro expectativas de la persona afectada, condicionando delicadas decisiones en diversos ámbitos (familiar, educativo, de salud, laboral, de seguros, etc. $)^{39}$. La adquisición de datos genéticos puede llevar a la estigmatización y discriminación de los individuos por motivos biológicos ${ }^{40}$.

Surgen así los problemas éticos y jurídicos basados en la protección de la intimidad genética ${ }^{41}$, la fiabilidad científica de los laboratorios y la creación de bases de datos genéticos ${ }^{42}$.

\section{b) Concepto y ámbito de la intimidad genética}

El derecho a la intimidad genética se puede definir como el derecho a determinar las condiciones de acceso a la información genética ${ }^{43}$. Su contenido se configura así sobre dos elementos: uno, de carácter subjetivo, y el otro, de carácter objetivo.

En su vertiente objetiva, según jurisprudencia del $\mathrm{TC}^{44}$ que ya tuvimos ocasión de comentar, el ámbito de la intimidad corporal constitucionalmente protegido, no es coextenso con el de la realidad física del cuerpo humano, al no ser una entidad física, sino cultural. Esta construcción, según RUIZ MIGUEL, es "necesaria pero insuficiente para enfrentarse a los peligros de la genética. De ahí la necesidad de una noción física y no sólo cultural de la intimidad corporal. (...) Ciertamente, lo usual es obtener el genoma de una persona con una intervención corporal, pero es perfectamente posible el análisis de datos

39 IÁÑEZ PAREJA, E., en Proyecto Genoma: Aspectos sociales y éticos. Instituto de Biotecnología. Facultad de Ciencias. Universidad de Granada.

${ }^{40}$ Pero también se puede plantear un derecho previo: el de no conocer. El derecho a no saber también constituye manifestación del derecho al respeto de la vida privada, ya reconocido por el Convenio Europeo para la Protección de los Derechos del Hombre y de las Libertades Fundamentales de 1.950 (art. 8.1). No se puede obligar a nadie a conocer datos sobre predisposiciones a enfermedades futuras que no tengan curación. Esto, sin embargo, alcanza ya a otras disciplinas, como la bioética jurídica y la medicina genómica.

${ }^{41}$ Ya sabemos que el genoma proporciona información sensible del individuo, pues puede dar a conocer sus futuras enfermedades y predisposiciones. Entraría también en juego el derecho al consentimiento informado.

42 Para DIEZ-PICAZO esta posibilidad es, cuando menos, discutible, y, en todo caso, de acceso restringido, teniendo que permanecer siempre bajo la salvaguarda de los órganos jurisdiccionales y permitiéndose el acceso a los mismos sólo por mandato de la autoridad judicial. Pero no sólo se trata de preservar un uso desviado de las informaciones, sino también de decidir si la posesión de las informaciones puede conciliarse con un sistema jurídico que respete la libertad de los individuos. Vid., DIEZ-PICAZO Y PONCE DE LEON, L., en El genoma humano y la identificación de la persona como problema jurídico, en la obra colectiva El derecho ante el Proyecto Genoma Humano, Ed. Fundación BBVA, vol. IV, págs. 107-108.

En relación con las bases de datos de ADN que puedan generarse como consecuencia de la práctica de este tipo de análisis en los procesos penales, debe tenerse presente la prohibición recogida en el art. 4.2 de la LO 15/99, de 13 de diciembre, de Protección de Datos de Carácter Personal, así como los puntos $3^{\circ}$ y $7^{\circ}$ de la $\mathrm{R}$ (92) 1 del Consejo de Europa.

${ }^{43}$ Según definición de RUIZ MIGUEL, C., en Los datos sobre características genéticas: libertad, intimidad y no-discriminación, en la obra colectiva Genética y Derecho, Ed. CGPJ . Estudios de Derecho Judicial, Madrid, 2.001, pág. 31.

${ }_{44}$ STC 207/96. El TC delimitó el verdadero contenido del derecho a la intimidad, distinguiéndolo de la intimidad corporal, como manifestación más restringida de aquél. 
DOI: http://dx.doi.org/10.12795/IETSCIENTIA.2017.i01.06

genéticos a partir de células o tejidos del sujeto obtenidos sin una intervención corporal (muestra de sudor, un cabello caído, etc.). Sin embargo, el hecho de que puedan obtenerse muestras con intervenciones corporales lícitas o incluso sin intervenciones de ese tipo, no puede significar que sea lícito acceder al genoma. En consecuencia, el elemento objetivo del derecho a la intimidad genética lo constituye el genoma humano en última instancia y, por derivación, cualquier tejido o parte del cuerpo humano en el que se encuentre esa información genética" ${ }^{\text {"45 }}$.

Pero no es fácil que el sujeto pueda percatarse de que su información genética está siendo obtenida o tratada sin su consentimiento. De esta manera, si el sujeto no conoce tal vulneración de su derecho, difícilmente puede reaccionar contra dicha lesión. La doctrina del TEDH y del propio TC sobre el secreto de las comunicaciones sería de aplicación analógica para el caso de realización de análisis genéticos, sobre todo si se realizan en el marco de un proceso penal. Así, según RUIZ MIGUEL ${ }^{46}$, todo análisis genético no consentido requerirá una intervención judicial, que, de forma motivada y respetuosa con el principio de proporcionalidad lato sensu, recoja una serie de datos tales como los siguientes: qué individuo y en qué condición procesal; qué datos genéticos se pretenden conocer; con relación a qué hechos; naturaleza y gravedad de los hechos que puedan hacer exigible tal análisis; quién debe efectuarlo y cómo; procedimiento de transcripción de los resultados; precauciones para conservar intactas y completas las muestras; casos en los que puedan o deban hacerse desaparecer los análisis efectuados; e indicación del modo de control judicial. También debería ser de aplicación, según este mismo autor, las teorías del derecho a la intimidad informática. De este modo, sería conveniente establecer procedimientos para acceder a la información que sobre nuestro genoma puedan poseer administraciones o particulares (habeas genoma) para rectificar las informaciones genéticas que puedan ser equivocadas y que puedan deparar graves perjuicios al sujeto, estableciendo procedimientos para cancelar la información genética que se posea; para la creación de ficheros, etc., etc., etc. ${ }^{47}$.

Por otro lado, el elemento subjetivo lo constituye la voluntad del sujeto de determinar quién y en qué condiciones puede acceder a la información sobre su genoma. Tal conocimiento o el tratamiento de la información genética sólo será lícito cuando se hagan con el consentimiento del sujeto ${ }^{48}$. Siendo un poder ejercitable por el titular, y como ya tuvimos ocasión de adelantar al tratar el derecho a la intimidad, éste se configura, a su vez, en una doble vertiente: negativa o de defensa, que supone el poder del titular para excluir a los demás del acceso o tratamiento de la información genética; y positiva, que implica la

\footnotetext{
${ }^{45}$ RUIZ MIGUEL, C., en Los datos sobre características genéticas..., op. cit., pág. 31.

${ }^{46}$ RUIZ MIGUEL, C., en Los datos sobre características genéticas ..., op. cit., pág. 36 y ss.

47 Con relación al derecho de rectificación y de acceso a este tipo de información recogida en ficheros, puede consultarse MARTIN-CASALLO LOPEZ, J. J., en Tratamiento automatizado de las bases de datos de ADN: régimen legal, Centro de Estudios Jurídicos del Ministerio de Justicia. Publicaciones año 2006; en página web www.cej.justicia.es, pág. 1843 y ss.

${ }^{48}$ Por aplicación análogica de la STC 207/1996, FJ 3ํ․
} 
DOI: http://dx.doi.org/10.12795/IETSCIENTIA.2017.i01.06

facultad de exigir la intervención de los poderes públicos para proporcionar una efectiva protección de la información genética ${ }^{49}$.

Con relación a los sujetos activos del derecho a la intimidad genética, de entrada resulta evidente que sólo las personas físicas, y no las jurídicas, tienen genoma humano, y, por tanto, sólo aquéllas y no éstas tienen derecho a la intimidad genética ${ }^{50}$.

Sin embargo, y respecto de los sujetos pasivos del derecho a la intimidad genética, es incuestionable que la dignidad humana debe ser respetada tanto por los poderes públicos como por los propios ciudadanos (arts. 9 y $10 \mathrm{CE}$ ), aún sin ser un derecho absoluto.

\section{c) ADN identificador}

Como hemos puesto de manifiesto, el daño potencial que puede resultar del acceso por terceros a la información genética resulta evidente si atendemos a su carácter altamente sensible, por la gran cantidad de información que las moléculas de ADN contienen y que pertenece a la esfera privada e íntima del individuo ${ }^{51}$. A los fines de identificación en el proceso, bastaría en principio con la práctica de un análisis que determinara la huella y no el mapa genético. El riesgo estriba en que una muestra sencilla (saliva, pelos, sangre...) podría llegar a afectar la esfera de la intimidad por los datos que pudieren llegar a transmitir ${ }^{52}$.

Por lo tanto, una cuestión que preocupa especialmente respecto de la intimidad genética, es ese potencial informativo que el análisis de ADN puede ofrecer. "La información sobre el genoma de un individuo representa la más íntima expresión de cuantos factores endógenos intervienen en la conformación de su estado de salud, no sólo actual, sino también futura,

\footnotetext{
49 Vid., RUIZ MIGUEL, C., en Los datos sobre características genéticas ..., op. cit., pág. 32 y ss. Entre las garantías que protegen el derecho a la intimidad genética, encontramos mecanismos de protección en el ámbito constitucional (derecho a la intimidad del art. 18.1 CE), que permite la utilización de todos los mecanismos constitucionales para lograr la efectividad del derecho; garantías en el orden civil (art. 1902 C.C.), y, por supuesto, en el orden penal, que quizás resulte insuficiente.

${ }^{50}$ Excedería de nuestro estudio analizar si el sujeto activo de este derecho lo es la "persona" física o el ser humano, o si este derecho debe ser reconocido a todo ser humano, sea cual sea el momento de su vida, y determinar el momento a partir del cual debemos o podemos hablar de "ser humano".

${ }^{51}$ Así lo reconoció la STS de 13 de marzo de 1989, al indicar que los datos de una persona se integran en el patrimonio de la intimidad personal (art. 18.1 CE), y, en consecuencia, también el perfil genético revelado por las técnicas de ADN. Vid., asimismo, STS de 4 de junio de 2003, respecto a la protección de la información sensible del individuo en las pruebas genéticas.

${ }^{52}$ Los marcadores que se deben utilizar a los fines de investigación de un delito no contienen información codificante, sino sólo ADN "chatarra" o no codificante, pudiéndose equiparar así claramente con las huellas dactilares, que tampoco proporcionan información "sensible" del individuo. En consecuencia, cierto sector doctrinal discute la incidencia en el derecho a la intimidad del individuo.
} 
calculando que unas 4000 enfermedades revisten carácter hereditario y que pueden quedar reflejadas en los análisis realizados" ${ }^{\text {"53. }}$.

Resultaba absolutamente imprescindible una regulación legal y taxativa en materia de investigación criminal para asegurar que sólo se utilizarían marcadores o loci cuyos alelos no fueran asociados a ningún tipo de información médica adicional, sea cual fuere el sistema que el legislador escoja, así como penalizar un uso espurio de esos marcadores. De este modo, el legislador español del $2007^{54}$ ha determinado expresamente qué tipo de información genética puede extraerse, teniendo en cuenta que el único fin es el de la identificación de los responsables criminales del delito que se investiga ${ }^{55}$.

El art. 4 de la LO 10/2007, establece que sólo se podrán inscribir en la base de datos de ADN, los identificadores genéticos que proporcionen, únicamente, información genética reveladora de la identidad de la persona y del sexo ${ }^{56}$; es decir, marcadores no codificantes, respetando así el derecho a la intimidad genética ${ }^{57}$. En consecuencia, el análisis genético en el proceso penal tiene que limitarse al fin de la mera identificación del imputado ${ }^{58}$, al llamado

53 DE SOLA, C., en Privacidad y datos genéticos. Situaciones de conflicto. En Revista de Derecho y Genoma Humano, vol. I. Bilbao, 1994, pág. 179.

${ }^{54}$ LO 10/2007, reguladora de la base de datos policial sobre identificadores obtenidos a partir del ADN, que en su art. 4 establece que la única información que puede acceder a la base de datos de ADN es la reveladora de la persona y su sexo.

${ }_{55}$ Nuevamente es de interés el apunte de LOPEZ-FRAGOSO, citando a VIGORINI, al decir que, desde la perspectiva contraria, como es el caso de Italia, se permite someter al imputado de determinados delitos contra la libertad sexual y que puedan suponer un riesgo de contagio o de transmisión de este tipo de patologías, a una pericia cuyo fin sea el de determinar su padecimiento de estas enfermedades. Vid., LOPEZ-FRAGOSO ALVAREZ, T., en Principios y límites..., op. cit., pág. 154. Este autor hace igualmente mención del régimen alemán, que autoriza expresamente el uso de la fuerza para la obtención de este tipo de muestras.

56 Sin embargo, la Exposición de Motivos de la LO 10/2007, Reguladora de la base de datos policial sobre identificadores obtenidos a partir del ADN, contempla la posibilidad de crear una base de datos en la que se almacene el conjunto de perfiles de ADN obtenidos, a fin de que éstos puedan ser utilizados en investigaciones "distintas o futuras", incluso sin el consentimiento del titular de los datos. En todo caso, el art. 5 de dicha ley establece que "corresponderá a la autoridad judicial pronunciarse sobre la ulterior conservación de dichas muestras o vestigios".

${ }^{57}$ La toma y archivo de las "huellas genéticas" sólo se justifica si se cumplen las previsiones legales para ello: necesidad de ley orgánica, por razón de su necesidad y proporcionalidad; sólo para la averiguación de delitos de cierta entidad etc. La posibilidad de archivar esta información genética no debe impedir al individuo el ejercicio de su "habeas genoma", para verificar los datos que se poseen, o incluso cancelarlos por el transcurso del tiempo. Así lo recoge la LO 10/2007, al establecer plazos para cancelación de los datos inscritos en las bases de datos de ADN, sometiéndose estos ficheros a los derechos de acceso, cancelación y rectificación, así como al nivel de seguridad que proporciona la LO 15/1999, de 13 de diciembre, de Protección de Datos de Carácter Personal.

${ }_{58}$ Única finalidad permitida por la R (92), como garantía del derecho a la intimidad personal, al determinarse el tipo de información que es lícito obtener cuando se analiza el ADN en el proceso penal. Hasta la LO 10/2007, esta previsión no existía en nuestro ordenamiento, aunque quedaba implícitamente aceptada por la jurisprudencia del TS sobre la base de que el fin que se pretende alcanzar con el análisis genético es únicamente identificar al imputado como el responsable de un ilícito penal. Los mismos protocolos de los laboratorios establecían igualmente esta limitación. Vid., STS de 13 de julio de 1992 y ATS de 10 de noviembre de 1993 (Sala $2^{a}$ ). De todas formas, es de interés el apunte de GARGANI, al decir "que existe un peligro potencial de intromisión en la intimidad de las personas aún cuando el ADN necesario para el análisis forense es el denominado no codificante, puesto que es fácil pasar del análisis de 
DOI: http://dx.doi.org/10.12795/IETSCIENTIA.2017.i01.06

ADN no sensible o también no codificante ${ }^{59}$, pues éste no contiene ninguna información sobre las enfermedades hereditarias que puedan afectar a un individuo. La información a nivel identificativo es alta y a nivel de información genética sobre enfermedades es prácticamente nula, al menos en la actualidad $^{60}$.

En definitiva, la prueba se puede y se debe hacer con técnicas meramente identificadoras, sin más información que la referida al elemento individualizador, pues no se debe minimizar el riesgo por el mero hecho de que las muestras de ADN que se utilizan son las denominadas "basura" (no codificantes), pues dentro de un futuro es posible que se obtenga información relevante de las muestras que, hoy por hoy, son consideradas carentes de proporcionar información sensible ${ }^{61}$, protegiendo de esta manera el derecho a la intimidad genética del individuo.

\section{BIBLIOGRAFIA CITADA}

ALONSO ALONSO, A., Una década de perfiles de ADN en la investigación penal y civil en España: La necesidad de una regulación legal, en la obra colectiva Genética y Derecho. Ed. CGPJ - Estudios de Derecho Judicial, Madrid, 2.001.

ALONSO ALONSO, A., Conceptos básicos de ADN forense. Estudios Jurídicos. 2004.

dicha parte del ADN al estudio del codificante (...). Para ello sólo se ha de utilizar, sobre la misma muestra, la sonda apropiada", según citado por LOPEZ-FRAGOSO ALVAREZ, T., en Principios y límites..., op. cit., pág. 153-154.

59 Como veremos, así lo establece también la LO 10/2007, si bien sólo establece que sólo podrán ser inscritos en la Base de Datos los perfiles de naturaleza no codificante.

60 Básicamente, y como norma general, sólo se realizará el análisis de poliformismos de ADN nuclear, pues son los que más información aportan, y, muy especialmente, la amelogenina. En otros casos será necesario el análisis del ADN mitocondrial (en el caso de grave degradación o antigüedad de las muestras, o si la cantidad de la que se dispone es mínima...). Se puede consultar el artículo de carácter eminentemente científico de ALONSO ALONSO, A., en Conceptos básicos de ADN forense, pág. 1860 y ss.

61 De ahí la enorme importancia de regular el tipo de información genética que se pueda obtener de un análisis de ADN en el campo de la identificación humana, restringiéndose al puramente identificativo.

Aunque resulte reiterativo, conviene recordar que los marcadores de ADN que deben utilizarse no proporcionan ninguna información médica sobre las personas y sólo tienen un valor identificativo. En este sentido, es exactamente igual que la huella dactilar. Recordemos que son poliformismos que se encuentran en intrones, es decir, partes no expresivas de los genes. Vid., GUILLEN VAZQUEZ, M.; PESTONI, C.; y CARRACEDO, A., en Bases de datos de $A D N$ con fines de investigación criminal: aspectos técnicos y problemas ético-legales, en Revista de Derecho y Genoma Humano, o 8, año 1998, pág. 140 y ss.

Una nueva línea de avance consiste en tratar de convertir la información del ADN en un retrato robot de la persona a quien pertenece, si bien para ello será necesario estudiar, no sólo el ADN "chatarra", sino también los genes. En todo caso, el retrato robot no sería muy fiable, pues es indudable que el ambiente lo modula casi todo. Como dato curioso, destacar que no sólo se han podido resolver casos criminales gracias al ADN de personas, sino también gracias al ADN de plantas, animales, etc. 
DOI: http://dx.doi.org/10.12795/IETSCIENTIA.2017.i01.06

ALVAREZ DE NEYRA KAPPLER, S., La prueba de ADN en el proceso penal. Ed. Comares. Granada, 2008.

ASENCIO MELLADO, J.Mª Valencia, 1988.

CHIERI, P. y ZANNONI, E.A., Prueba del ADN. 2 ${ }^{\text {a }}$ ed. Ed. Astrea, Buenos Aires, 2001.

DE SOLA, C., Privacidad y datos genéticos. Situaciones de conflicto. Revista de Derecho y Genoma Humano, vol. I. Bilbao, 1994.

DEL MORAL GARCIA, A., Intervenciones corporales: reflexiones ante la inminente enésima reforma de la Ley de Enjuiciamiento Criminal. Ponencia presentada al Curso Constitución y Garantías Penales, CGPJ, noviembre de 2003.

DIEZ-PICAZO Y PONCE DE LEON, L., El genoma humano y la identificación de la persona como problema jurídico. En la obra colectiva El derecho ante el Proyecto Genoma Humano, Ed. Fundación BBVA, vol. IV.

FORCADA JORDI, M., Las inspecciones o registros corporales sobre la propia persona. Revista La Ley no 2604, de 26 de octubre de 1990.

GARGANI GARGANI, A., La identificación mediante pruebas genéticas en el derecho italiano: problemas y perspectivas, en la obra colectiva El Derecho ante el Proyecto Genoma Humano. Ed. Fundación BBVA, vol. IV.

GIL HERNANDEZ, A., Intervenciones corporales y derechos fundamentales. Ed. Colex, Madrid, 1995.

GONZALEZ-CUELLAR SERRANO, N., Proporcionalidad y derechos fundamentales en el proceso penal. Ed. Colex, Madrid, 1992.

GUILLEN VAZQUEZ, M.; PESTONI, C.; y CARRACEDO, A., Bases de datos de $A D N$ con fines de investigación criminal: aspectos técnicos y problemas ético-legales. Revista de Derecho y Genoma Humano, no 8, año 1998.

HERRERO-TEJEDOR ALGAR, F., Intervenciones corporales: jurisprudencia constitucional. Centro de Estudios Jurídicos del Ministerio de Justicia. Publicaciones año 2006; en página web www.cej.justicia.es.

IÁÑEZ PAREJA, E., Proyecto Genoma: Aspectos sociales y éticos. Instituto de Biotecnología. Facultad de Ciencias. Universidad de Granada.

LIBANO ALONSO, A., Bancos de archivos de perfiles de ADN. Revista de Derecho Médico y Legislación Sanitaria, año 1999.

LOPEZ BARJA DE QUIROGA, J., y RODRIGUEZ RAMOS, L., La intimidad corporal devaluada.- Comentario a la sentencia $n^{\circ}$ 37/1989 de 15 de febrero, del TC. Poder Judicial, 1989.

LOPEZ-FRAGOSO ALVAREZ, T., Las intervenciones telefónicas en el proceso penal. Ed. Colex, Madrid, 1991.

LOPEZ-FRAGOSO ALVAREZ, T., Principios y límites de las pruebas en el proceso penal. En la obra colectiva Genética y Derecho. Ed. CGPJ - Estudios de Derecho Judicial, Madrid, 2.001.

MARTIN-CASALLO LOPEZ, J. J., Tratamiento automatizado de las bases de datos de ADN: régimen legal. Centro de Estudios Jurídicos del Ministerio de Justicia. Publicaciones año 2006; en página web www.cej.justicia.es.

MORENO VERDEJO, J., ADN y proceso penal: análisis de la reforma operada por la ley orgánica 15/2003, de 25 de noviembre. Ed. Centro de Estudios 
Jurídicos del Ministerio de Justicia. Publicaciones año 2006; en página web www.cej.justicia.es.

MORENO VERDEJO, J., y GUILLEN VAZQUEZ, M., ADN y proceso jurisdiccional: excesos y defectos: necesidad de superar la actual situación de anomalía. En Revista de Derecho Penal - Práctica Penal, Ed. SEPIN (Penal), № 1 , enero-febrero 2.003 .

NARVAEZ RODRIGUEZ, A., ADN e investigación penal: su necesaria regulación legal. Revista del Centro de Estudios Jurídicos de la Administración de Justicia, $1^{\circ}$ semestre de 2.003.

RUIZ MIGUEL, C., Los datos sobre características genéticas: libertad, intimidad y no-discriminación, en la obra colectiva Genética y Derecho. Ed. CGPJ Estudios de Derecho Judicial, Madrid. 